\title{
ERnSt JÜnger entre la Primera y SEgunda GUERRA MUNDIAL
}

\section{ERNST JÜNGER BETWEEN THE FIRST AND SECOND WORLD WAR}

\author{
LUIS DURÁN GUERRA \\ Universidad de Sevilla \\ ludovicusdurandus@gmail.com
}

\begin{abstract}
RECIBIDO: 09/05/2021
\end{abstract}
ACEPTADO: 01/09/2021

Resumen: Este trabajo trata sobre la evolución ideológica de Ernst Jünger entre la Primera y la Segunda Guerra Mundial: desde el realismo heroico de Tempestades de acero al "exilio interior" de un esteta en guerra en sus Diarios de la Segunda Guerra Mundial. Se considera la relación con el dolor motivada por la supremacía de la técnica como la causa que habría llevado a Jünger a modificar su visión de la guerra bajo el régimen nacionalsocialista. En ambos casos, la experiencia de la guerra le ha servido a su autor para crear las figuras esenciales de su pensamiento filosófico: el Soldado Desconocido, el Trabajador y el Emboscado.

Palabras-clave: Emboscado; Primera Guerra Mundial; Segunda Guerra Mundial; Soldado Desconocido; Trabajador.

\begin{abstract}
This paper deals with the ideological evolution of Ernst Jünger between the First and Second World War: from the heroic realism of The Storms of Steel to the "internal exile" of an esthete at war in their Second World War diaries. In both cases, the experience of war has served the author to create the essential figures of his philosophical thought: the Unknown Soldier, the Worker and the Rebel.
\end{abstract}

Key-words: Rebel; First World War; Second World War; Unknown Soldier; Worker. 
Si bien la relación hombre/máquina estuvo presente desde un principio en su filosofía de la guerra, el problema de la técnica no fue el gran tema de la "novela del frente" de Ernst Jünger -ni mucho menos el motivo principal que le indujese a participar como voluntario en la Primera Guerra Mundial. En efecto, vivida al principio como una mera "aventura", Jünger habría pasado gradualmente de plantearse la moral del heró́smo en medio de la "batalla de material" a ver en el "carácter total de trabajo" de la guerra industrial moderna el auténtico espíritu de la época. Así pues, solo cuando el autor de Tempestades de acero aceptó la impotencia de la "persona singular" ante el destino técnico del mundo como "movilización total", se volvió insostenible la visión heroica de la guerra mantenida en sus primeros libros.

En este artículo se realiza una semblanza de la evolución de la actitud ante la guerra de Jünger. La experiencia del dolor se toma como hipótesis interpretativa para explicar el desconcertante cambio en la valoración del fenómeno bélico por parte del escritor alemán a finales de los años treinta. En este sentido, si bien la Primera Guerra Mundial pudo aún cumplir las expectativas del ideal heroico del joven Jünger, la victoria final de la máquina sobre el ser humano en vísperas de la Segunda Guerra Mundial, representada por el dominio técnico de la Figura del Trabajador, transforma el heroísmo trágico del Soldado Desconocido en la "resistencia espiritual" del Emboscado al poder del nihilismo. En definitiva, si el "realismo heroico" había estilizado la potencia y el activismo del guerrero, en el Tercer Reich, un Jünger transformado por el dolor y el sufrimiento, no tuvo otra opción que revestir de una dimensión estética las actitudes opuestas: la impotencia y la pasividad ante la catástrofe reflejadas en sus Diarios de la Segunda Guerra Mundial. 


\section{La figura de la Primera Guerra Mundial: el Soldado Desconocido}

... ¿cuándo acaba esta mierda de guerra?

E. Jünger, Diario de guerra, 24-V-17

En El estallido de la guerra de 1914, un texto editado por vez primera en 1934 e incluido en la edición castellana de Tempestades de acero, Ernst Jünger recordaba emocionado la euforia que embargaba a los hombres de su generación en los días previos al inicio de un conflicto del que no hace mucho que se ha conmemorado el primer centenario. Aquel verano, Jünger no se había ido de vacaciones, como todos los años, con sus padres y hermanos. Tenía que preparar el examen final de bachillerato, pues si aprobaba, así se lo había prometido el padre tras su loca aventura un año antes en la Legión Extranjera, podría viajar libremente por el mundo. Sentado en el tejado de la casa familiar en Rehburg, que estaban reparando tras haber sufrido un incendio el año anterior, Jünger conversaba apaciblemente con los obreros cuando de pronto pasó por debajo el cartero gritando desde su bicicleta: “¡Orden de movilización!"”.

Aquellas tres palabras animaron al joven Jünger a participar en la guerra como voluntario en el Kaiserliches Heer, "decisión que adoptaban", como él mismo apunta, "a aquella misma hora centenares de miles de hombres". Al día siguiente, nuestro aventurero de diecinueve años viaja en tren a Hannover para alistarse en un regimiento. Lo que allí vio hay que dejarlo por una vez a la vivaz espontaneidad de su elocuente pluma: "Por la Plaza de Ernesto-Augusto pasaba desfilando un regimiento que marchaba al frente. Los soldados cantaban, entre sus filas se habían introducido señoras y muchachas y los adornaban con flores. Desde entonces he visto muchas multitudes arrebatadas de entusiasmo; 
ningún otro ha sido tan hondo y poderoso como el de aquel día" (Jünger, 1998, p. 247). ${ }^{1}$

Declarado apto por el $73^{\circ}$ Regimiento de Fusileros, Jünger no se incorporó de inmediato al frente, sino que tuvo que esperar al 6 de octubre para poder presentarse en el cuartel, tiempo que aprovecharía para terminar rápidamente el bachillerato $\mathrm{y}$ matricularse en la universidad de Heidelberg. Durante el período de instrucción, el joven soldado entra en contacto con la disciplina prusiana a la que confiesa deberle, no obstante haber chocado al principio con sus normas, "más que a todos los maestros de escuela y a todos los libros del mundo". Por fin, el 27 de diciembre sube al tren que lo llevará junto a su unidad al frente de la gredosa Champaña, pero no sin antes haberse guardado en el bolsillo de la guerrera una libreta destinada a reflejar sus impresiones durante la contienda. "Sabía que nunca más volverían las cosas que nos aguardaban y me encaminaba hacia ellas con suma curiosidad". Como si quisiera resolver con su propio ejemplo personal el viejo conflicto de las armas y las letras, contemplación y acción no estuvieron reñidas nunca para Jünger que ya desde su primera experiencia en el campo de batalla supo conciliarlas en la vida y en la obra.

$$
*
$$

${ }^{1}$ De aquel entusiasmo fue testigo incluso alguien tan poco sospechoso de militarismo como Zweig (2001, p. 286): “... debo confesar que en aquella primera salida a la calle de las masas había algo grandioso, arrebatador, incluso cautivador, a lo que era difícil sustraerse. Y, a pesar del odio y la aversión a la guerra, no quisiera verme privado del recuerdo de aquellos primeros días durante el resto de mi vida; miles, cientos de miles de hombres sentían como nunca lo que más les hubiera valido sentir en tiempos de paz: que formaban un todo,... sentían... que todos estaban llamados a arrojar su insignificante 'yo' dentro de aquella masa ardiente para purificarse de todo egoísmo. Por unos momentos todas las diferencias de posición, lengua, raza y religión se vieron anegadas por el torrencial sentimiento de fraternidad". 
Como es sabido, el resultado de esas "anotaciones diarias" son los catorce cuadernos que están en la base de la que es para muchos la mejor obra narrativa de la denominada "novela del frente": Tempestades de acero, la cual ha llegado a conocer hasta seis versiones diferentes desde su primera edición en 1920, habiéndose publicado en 2010 el manuscrito original, disponible ahora también en español bajo el título Diario de guerra (1914-1918). ${ }^{2}$ En las primeras páginas de aquel impactante libro, Jünger describía así los sentimientos de los hombres de su generación al partir hacia la guerra:

Crecidos en una era de seguridad, sentíamos todos un anhelo de cosas insólitas, de peligro grande. Y entonces la guerra nos había arrebatado como una borrachera. Habíamos partido hacia el frente bajo una lluvia de flores, en una embriagada atmósfera de rosas y sangre. Ella, la guerra, era la que había de aportarnos aquello, las cosas grandes, fuertes, espléndidas. La guerra nos parecía un lance viril, un alegre concurso de tiro celebrado sobre floridas praderas en que la sangre era el rocío (Jünger, 1998, p. 10). ${ }^{3}$

El inicial entusiasmo patriótico, con todo, irá disminuyendo en todos aquellos hombres a medida que la guerra ofensiva se fue convirtiendo en una cruel y encarnizada lucha de posiciones. En los tres años y nueve meses que Jünger estuvo en la guerra llegó a participar en varias peligrosas patrullas y en ocho grandes batallas: en la guerra de trincheras en la Champaña y en el Artois, en la Batalla del Somme, en Flandes y en Cambrai, en la Operación Michael, así como en los últimos combates defensivos. Herido hasta en catorce ocasiones, nuestro voluntario había ascendido de soldado raso a alférez y jefe de compañía de su unidad, llegando a

\footnotetext{
${ }^{2}$ Jünger (2013; bibliografía específica en pp. 661-667). Véase King (2003).

${ }^{3}$ Véase J. Volmert (1985). Para la escritura de guerra como instrumento de reflexión en Jünger, véase, por ejemplo, Rodríguez Suárez (2013).
} 
estar encuadrado en las Sturmtruppen, las famosas tropas de asalto alemanas, donde se hizo merecedor por su valor de las más altas condecoraciones, entre ellas la más prestigiosa Orden Pour le Mérite, concedida solo por el propio Káiser. Desde la primera línea de combate, en trincheras, hospitales y subterráneos, el joven Jünger describe en sus diarios esta experiencia bélica escalofriante, la cual reconstruyó literariamente en su mítica obra Tempestades de acero, donde, no obstante las escasas referencias a la cronología de los hechos, apreciamos todo el horror que entrañó aquel infierno que llamaron la Gran Guerra.

Ahora bien, Tempestades de acero no representa la única obra de Jünger dedicada a la Primera Guerra Mundial. Entre los textos más famosos del período de entreguerras impregnados por la experiencia del frente hay que recordar asimismo El bosquecillo 125 (1925), Fuego y sangre (1925), El corazón aventurero (1929), La movilización total (1930), El trabajador (1932), Sobre el dolor (1934), por no referir las consideraciones teóricas sobre el conflicto bélico que Jünger alojó en el inclasificable ensayo La lucha como vivencia interior (1922) o su particular pronóstico de las guerras futuras en el artículo Fuego y movimiento (1930). En La lucha como vivencia interior, donde las páginas narrativas se combinan con la crónica y el diario, hallamos un pasaje que define la impronta que, a juicio de su autor, dejó la contienda bélica en el espíritu de los excombatientes:

Todavía nunca una generación volvió sobre sus pasos desde una puerta tan lóbrega y violenta como la de esta guerra para entrar a la luz de la vida. Y esto no lo podemos negar, por mucho que más de uno lo desease de buena gana: la guerra, padre de todas las cosas, es también nuestro progenitor; nos ha forjado a martillazos, nos ha cincelado y fraguado tal como somos [...] Nos ha educado para la lucha y seguiremos siendo 
luchadores mientras sigamos siendo quienes somos (como se cita en Ocaña, 1993, p. 208, n. 12). ${ }^{4}$

Como se puede apreciar, Jünger se negó a condenar abiertamente la guerra, especialmente en los años veinte y primeros treinta, pero lo que aquí me interesa subrayar son las imágenes tomadas del mundo del trabajo para caracterizar aquella experiencia. El "belicismo" jüngeriano, con todo, es especialmente visible en el ensayo mencionado La luch a como vivencia interior, traducida al francés en 1934 con el desafortunado título La Guerre notre mère. Por la truculencia expresionista de las imágenes allí exhibidas resulta oportuno traerlo a la memoria de todos para hacerse una idea lo más ajustada posible del "activismo heroico" de Ernst Jünger en sus libros anteriores a 1939. Para lo escrito por él en estos pasajes de La lucha como vivencia interior no habría otra calificación que la expresada en una carta de 1945 por Thomas Mann, quien a pesar de reconocer su "extraordinario talento literario", no puede por menos que tacharle "como un precursor del nazismo y un gélido sibarita de la barbarie". 5

La lectura de este exaltado canto a Marte, de este lirismo de la barbarie, nos inspira hoy la misma repulsa que las Bagatelas para una masacre de Céline. "Las grandes batallas revisten una majestad eterna que domina la trama ininterrumpida de la historia", escribe Jünger con gran solemnidad. Se expresa aquí una visión belicista del mundo y un concepto monumental de la historia que trae por un momento remembranzas de la filosofía del espíritu de Hegel, para quien la vida de los individuos con sus pasiones sólo cuenta en la medida en que sirve como medio para el progreso de la historia del

${ }^{4}$ Entretanto se ha traducido también su novela corta Sturm (1923), la cual tiene asimismo como trasfondo la Gran Guerra y cuyo protagonista no es otro que el alter ego de Jünger. Véase Jünger (2014).

5 Thomas Mann a Friedrich Krause, Pacific Palisades (Los Ángeles), 10 de octubre de 1945, como se cita en Blumenberg (2010, p. 65). 
mundo. Pero en lugar de tener su fundamento en la "astucia de la razón", Jünger, que ha pasado por la escuela de Schopenhauer y Nietzsche, no identifica el supuesto fin al que sirven los individuos como instrumentos con la idea de progreso, sino con la "de una Voluntad Superior".

Ahora bien, si el vitalismo nietzscheano (no así la ética de la compasión schopenhaueriana) ha desempeñado un papel en la asunción del llamado realismo heroico de Jünger, desde luego éste no parece suficiente para entender la filosofía de la guerra del autor de La lucha como vivencia interior. ${ }^{6}$ En efecto, el joven Jünger comparte con el autor del Zaratustra la concepción de la vida como voluntad de poder así como la idea del superhombre, pero se desmarca de éste tanto por la impronta nacionalista que reviste su cosmovisión agonista como por la metafísica irracionalista inherente a la inconmovible convicción de que esta vida es la manifestación de una idea superior, según la cual la materia no es nada y el espíritu lo es todo. La experiencia de la guerra de trincheras le habría llevado, desde este idealismo romántico, no sólo a ver lo ideal en lo real, sino a representarse incluso al héroe como un órganon a través del cual se expresa aquella idea o espíritu. Una idea a la que el guerrero dice poder servir "con todos los medios del espíritu y de la violencia, hasta el lanza-llamas y el ataque con gases" y que nos hace ver al adversario, no como hombre, sino como un mero principio abstracto susceptible de ser aniquilado. La misma idea que hacía comprender al soldado

\footnotetext{
${ }^{6}$ Véase Béland (2009, 31-51) sobre la amalgama de vitalismo nietzscheano y de idealismo romántico en la filosofía del joven Jünger; Rossi (2003, p. 52): "la idea de que la lucha es constitutiva de la realidad y se manifiesta a todos los niveles de ella -esto es, entendida como una especie de principio cósmico- ya puede encontrarse en los escritores románticos". Agradezco al profesor Rossi su gentileza enviándome su artículo desde la Argentina, así como sus valiosos comentarios que han permitido la mejora sustancial de este trabajo.
} 
filósofo la vida como guerra y al ser humano, finalmente, como "receptáculo de valores eternos e indestructibles".

Entre las batallas revestidas con aquella majestad eterna hay que tener en cuenta, sin duda, las de la Primera Guerra Mundial. “¿Hasta cuándo deberemos esperar que acontecimientos tan magníficos como la gran batalla de la primavera de 1918, o la batalla naval de Skagerrak, se erijan por encima de los tiempos como monumentos que el hombre no puede tocar?", se pregunta el autor de Tempestades de acero en un intento casi desesperado por salvar la monumentalidad de las hazañas bélicas del catorce. Jünger se ufana de sus heridas y de la emoción que le embargaba en la batalla, "tan diferente de la resignación eslava frente al sufrimiento", escribe de acuerdo con los tópicos de la psicología racial vigentes en su tiempo. Subraya a continuación el salvajismo atávico que se esconde tras la delgada capa de la civilización moderna que hace inevitables las guerras y donde el objetivo no es otro que "el aniquilamiento del adversario". Ahora bien, ¿no constituye este concepto -aniquilamiento del adversario- el corolario nihilista de la Gran Guerra, laboratorio de la guerra total que la Segunda Guerra Mundial pondría en práctica por medio de las modernas armas (gases venenosos, aeroplano, submarino y carros de combate) estrenadas y ensayadas entre 1914 y 1918? En efecto, aunque Jünger no parece adoptar aún una postura crítica al respecto, la batalla de material de la nueva guerra tecnificada serviría únicamente a este desalmado objetivo: "Con el material queremos aplastar al adversario, cegarlo, ahogarlo, hacerle morder el polvo, abatirlo por tierra, envolverlo en llamas, triturarlo en los agujeros, exterminarlo". Solo en los últimos combates de 1918, cuando se perfiló la imagen de la batalla mecánica del futuro, pudo verse claro que el valor del oficial de infantería solo puede manifestarse a través de los medios que la técnica bélica ponía a su 
disposición. Jünger fue consciente de ello a más tardar en $E l$ bosquecillo 125:

Pero nuestra época trabaja con medios poderosos, y, cuando se combate por un espantoso campo de escombros en el que se enfrentan dos imágenes del mundo, lo que importa no son los millares de seres humanos que tal vez podrían ser salvados de la destrucción; lo que importa es que la docena de hombres supervivientes se halle lista en el lugar preciso y pueda arrojar en un platillo de la balanza el peso decisivo de sus ametralladoras y granadas de mano (Jünger, 1998, p. 183).

El ideal heroico no podía separarse de la relación hombre/máquina. No obstante, la técnica no parece desempeñar en La lucha como vivencia interior un papel decisivo, pues ya sea que esgrima un hacha o una granada de mano, lo que cuenta es la sed de sangre de los combatientes en el enfrentamiento cuerpo a cuerpo. O dicho de otra manera: lo que cuenta, en definitiva, es el hombre. "Sí, de sed de sangre", escribe el que habría de ser galardonado en 1982 con el Premio Goethe. Y añade extáticamente en lenguaje expresionista: "La voluptuosidad de la sangre flota por encima de la guerra como una vela roja sobre una galería sombría". Por mucho que se haya podido ver "dans ses écrits de guerre une trace de la sagesse goethéenne" (Béland, 2009, p. 44), no cabe imaginar una imagen más contraria al espíritu de Goethe, ese "gran pacifista" como lo llamó Thomas Mann, aborrecedor de la sangre derramada no menos que del culto romántico de lo heroico y caballeresco. El 21 de marzo de 1918, antes de la primera gran ofensiva de la llamada Kaiserschlacht, anotaba el soldado en su Diario de guerra: "Con una mezcla de sentimientos producidos por la excitación, la sed de sangre, la cólera y el consumo de alcohol, nos lanzamos al paso contra las líneas enemigas" (Jünger, 2013, p. 370). ${ }^{7}$ Las últimas

\footnotetext{
${ }^{7}$ Véase su descripción correspondiente de la Operación Michael en Tempestades de acero, donde se ha suprimido esta expresión de sed vampírica. En su lugar
} 
palabras de La lucha como vivencia interior muestran, por lo demás, que lo último que le interesaba a Jünger destacar en esa ocasión eran las consecuencias políticas y culturales de la guerra de 1914-18: "Pero aquellos que han visto en la última guerra sólo un desafío lanzado a la civilización, aquellos que únicamente han sentido y conservado la amargura de su propio sufrimiento, ésos han vivido como esclavos. No tuvieron Vida Interior, sino solamente una existencia pura y tristemente material".

El militarismo de los años veinte se reafirma al comienzo de los treinta. En 1930 Jünger edita el volumen colectivo Krieg und Krieger, donde él mismo publica un ensayo titulado $L a$ movilización total, precedente inmediato de su obra teórica más ambiciosa, El trabajador. El nuevo "misticismo bélico" que contenían aquellas páginas mereció una crítica muy dura por parte de Walter Benjamin, quien no dudó en denunciar cada una de las imposturas de aquellos vástagos del nacionalismo idealista alemán (Benjamin, 1991, pp. 47-58). Sin perjuicio de los puntos de contacto existentes entre Jünger y Benjamin en el diagnóstico de la época, la exaltación de la tradición heroica de la Gran Guerra y del "aura" del guerrero denunciada por el filósofo marxista ponía en evidencia la "ceguera histórica" de Jünger y su "círculo", cuando no su aproximación a la propaganda nazi. Según Benjamin, lo que demuestra la indigencia de la imagen de la guerra presentada por los autores de Krieg und Krieger es, cuanto menos, "lo poco que sus experiencias le han servido para aprehenderla". Las palabras de Jünger "el siglo, las ideas y las armas con las que se lucha son de importancia secundaria", citadas por el filósofo alemán, son un buen ejemplo de ello.

dice: "Mientras íbamos avanzando se apoderó de nosotros una ira propia de energúmenos. Un poderosísimo deseo de matar daba alas a nuestros pies. La rabia me arrancaba lágrimas amargas" (Jünger, 1998, p. 142). 
Pero quizá los textos más contundentes indirectamente contra la guerra como "experiencia interior" sean aquellos otros en los que como en Experiencia y pobreza (1933) o en El narrador (1936), Benjamin constata la destrucción de la experiencia que la Primera Guerra Mundial había dibujado en el paisaje mental de los excombatientes:

Con la Guerra Mundial comenzó a hacerse evidente un proceso que aún no se ha detenido. ¿No se notó acaso que la gente volvía enmudecida del campo de batalla? En lugar de retornar más ricos en experiencias comunicables, volvían empobrecidos. Todo aquello que diez años más tarde se vertió en una marea de libros de guerra, nada tenía que ver con experiencias que se transmiten de boca en boca. Y eso no era sorprendente, pues jamás las experiencias resultantes de la refutación de mentiras fundamentales, significaron un castigo tan severo como el infligido a la estratégica por la guerra de trincheras, a la económica por la inflación, a la corporal por la batalla material, a la ética por los detentadores del poder. Una generación que todavía había ido a la escuela en tranvía tirado por caballos, se encontró súbitamente a la intemperie, en un paisaje en que nada había quedado incambiado a excepción de las nubes. Entre ellas, rodeado por un campo de fuerza de corrientes devastadoras y explosiones, se encontraba el minúsculo y quebradizo cuerpo humano (1991, p. 112).

Lo que había saltado por los aires en la guerra era la misma noción de experiencia. Y lo que se había puesto de manifiesto al término del conflicto, en palabras de Freud, era "nuestra decepción ante la guerra", pues la "miseria anímica" de esta época afectaba por igual a combatientes y no combatientes (Freud, 1996, pp. 96-123). ${ }^{8}$ Jünger no podía generalizar lo que era fruto de una "experiencia" singularísima, si bien podría citarse a autores cercanos a su "activismo heroico", por lo demás muy dispares entre sí, como

${ }^{8}$ Véase también su Warum Krieg?, la respuesta a una carta de Einstein de 30 de julio de 1932 en la que el célebre físico le invitaba a reflexionar sobre la guerra (Freud, 1973, pp. 3207-3215). 
Gabriele D'Annunzio, Oskar Kokoschka y Filippo Tommaso Marinetti. En lo que respecta a la experiencia guerrera (Kriegserlebnis) de Jünger vale la observación escéptica de Blumenberg: "Habrá que acreditar si la experiencia más genuina de Jünger puede ratificarse en el espíritu de la época" (2010, p. 16). A años luz del realismo heroico jüngeriano, por ejemplo, la visión del conflicto de Erich Maria Remarque, quien sólo tuvo una corta experiencia como zapador en la guerra del catorce, se había anticipado ya al pronóstico pesimista de Benjamin. En su célebre novela Sin novedad en el frente (1929) leemos sobre el futuro que esperaba a los supervivientes de la masacre:

Tampoco nos comprenderá nadie; tenemos delante una generación que, ciertamente, ha vivido estos años con nosotros, pero ya tenía hogar y profesión y regresará ahora a sus antiguas posiciones, en las que olvidará la guerra; detrás de nosotros sube otra, parecida a la que formábamos, que nos resultará extraña y nos arrinconará. Estamos de más incluso para nosotros mismos. Envejeceremos; algunos se adaptarán, otros se resignarán y la mayoría quedaremos absolutamente desamparados. Se escurrirán los años y, por fin, sucumbiremos (Remarque, 1984, p. 187). ${ }^{9}$

Jünger envejeció hasta alcanzar casi los ciento tres años, pero ni se adaptó ni se resignó ni quedó totalmente desamparado, sino que siguió viviendo durante el período de entreguerras como oficial de la Reichswehr (1918-1923), matriculándose acto seguido en la Universidad de Leipzig para estudiar biología, zoología y filosofía e iniciando durante los convulsos años de la República de Weimar una intensa actividad publicista estrechamente ligada a los grupúsculos nacionalistas de la llamada "revolución

${ }^{9}$ Sobre Jünger-Remarque véase Kunicki (1999, pp. 291-308). 
conservadora". ${ }^{10}$ Tres años después de su muerte aparecieron estos "artículos malditos" que el autor se había negado a incluir en la edición de sus Obras Completas (Jünger, 2001). La lectura de los mismos, por incómoda que resulte, no puede hacer dudar a nadie de la responsabilidad de Jünger en la destrucción de la democracia alemana. En sus artículos políticos, adhiere a la tesis de la "puñalada por la espalda" (Dolchstoss) como causa de la derrota de Alemania en la Primera Guerra Mundial, para acabar formulando la que es la hipótesis central de La movilización total, según la cual la guerra se pierde debido a que la movilización de la nación fue solo parcial. Durante este polémico período de su vida, el joven Jünger incorpora la fotografía a su escritura de guerra. De los cuatro álbumes fotográficos que él mismo edita de 1930 a 1933, dos versan explícitamente sobre la Primera Guerra Mundial: El rostro de la guerra mundial. Vivencias del frente de los soldados alemanes (1930) y Aqui habla el enemigo. Vivencias de la guerra de nuestros adversarios (1931). ${ }^{11}$ Jünger seleccionó cerca de cuatrocientas fotos para confeccionar sus dos fotolibros, tomando algunas de ellas del monumental Grosser Bilderatlas des Weltkrieges 1914-19. Ahora bien, frente al pictorismo o el costumbrismo local de gran parte de estas fotos y a las muy frecuentes imágenes de pose, "las fotos que Jünger elige", escribe Sánchez Durá,

${ }^{10}$ Véase Mohler (1950); Dupeaux (1992); Breuer (1996). Véase sobre este nacionalismo de nuevo cuño en Jünger, no obstante su brevedad, Abellán (1977; bibliografía en p. 268).

${ }^{11}$ Véase la edición castellana de ambos álbumes en Sánchez Durá (2002). Los otros dos fotolibros editados por Jünger, El instante peligroso (1931) y El mundo transformado. Cartilla ilustrada de nuestro tiempo (1933), si bien no tratan de la guerra del catorce como tal no dejan de tenerla muy presente. Véase Jünger (2005). Véase, por ejemplo, Werneburg (1992, pp. 42-64). 
subrayan el instante peligroso del estallido o del impacto, la nueva relación de las armas con el espacio, la transformación de la guerra en guerra de materiales, la devastación masiva, el momento de la acción, las tropas en sus momentos estratégicos o tácticos y la conversión de los guerreros en soldados. Es decir: la guerra no como enfrentamiento entre guerreros que aún en su lucha a muerte se reconocen en tanto individuos, sino como soldados cuyo fuego indistinto indistintamente destruye a un enemigo configurado en masa, espacio y recursos abstractos que aniquilar (2001, p. 153).

Así pues, la mitificación del guerrero que le ha granjeado, en última instancia, la acusación de "fascismo estético" parece haber sido superada o por lo menos contrastada con otros aspectos no menos relevantes de la experiencia bélica. ${ }^{12}$ La técnica se presenta en estos álbumes como el verdadero uniforme del trabajador $\mathrm{y}$, por consiguiente, también del soldado, ese "asalariado de la muerte", como leemos en La lucha como vivencia interior. $\mathrm{Y}$ si bien no reniega del realismo heroico de su juventud, tampoco cae en una trivial glorificación de la guerra. Jünger parece reconocer a regañadientes que en la lucha librada en las "batallas de material" (Materialschlachten) entre ser humano y máquina es ésta la que al final consiguió alzarse con la victoria. En su ensayo de 1934 Sobre el dolor, el autor no abrigará ya más dudas al respecto: la guerra industrial moderna impide hablar siquiera de alzamiento de un pueblo en armas en sentido tradicional. De hecho, desde que celebrasen sus bodas de sangre en la guerra del catorce, técnica y nihilismo constituyen un binomio sobre el que el solitario de Wilflingen no habría dejado nunca de reflexionar. Y así, cuando ya había alcanzado la "edad de los patriarcas", al serle preguntado sobre el efecto que le causaba pensar de nuevo sobre el tema de la guerra, quiso aclarar a sus entrevistadores:

${ }^{12}$ Sobre la transformación que experimenta la noción de "lucha" en las obras del joven Jünger es recomendable Rossi (2003). 
Ante todo quiero precisar una cosa: para mí, el verdadero gran motivo de interés ha sido la técnica, cuya potencia se ha manifestado de manera impresionante en la guerra mundial de 1914-18, la primera "guerra de materiales". Se trató de un conflicto profundamente distinto de todos los anteriores, porque el choque no se produjo solamente entre ejércitos, sino entre potencias industriales. Ante aquel escenario mi visión de la guerra asumió la forma de un activismo heroico (Gnoli y Volpi, 1998, pp. 2021).

Ahora bien, lo que movió al principio a Jünger a semejante activismo no fue la técnica como objeto teórico, sino la voluntad de sobresalir por su coraje entre tantos soldados desconocidos. Sin embargo, no parece cuestionar el hecho de que el febril movimiento del Sturmtruppenführer en medio del fuego de la batalla de material, tiene que sonar necesariamente a temeridad suicida en un escenario donde, como él mismo reconoce, habría sido necesario poseer una valentía superior a la de los héroes homéricos. Y así, sobrevivir a esta guerra no dependía tanto del valor como del azar: "Ahora podría yacer en tierra con los miembros contraídos como el muerto con en el que había tropezado en la trinchera. [...] Un segundo antes, un metro más allá: eso era lo decisivo" (Jünger, 2014, p. 70; la cursiva es mía). Con todo, la Gran Guerra habría servido para que Jünger tuviese una experiencia que podemos considerar genuina: la experiencia interior del dolor y de lo elemental que está en la base del primer gran símbolo de su imaginario poético-filosófico: la Figura del Soldado Desconocido. Desde este punto de vista, la imagen de la época no reposaría tanto (aunque Jünger no parece extraer esta conclusión) en la "vivencia interior" del guerrero que vence sobre su adversario como en el Soldado Anónimo que cae solo en el campo de batalla sin que nadie pueda darle sepultura. Para nuestro escritor, esta figura sólo conviene a la Primera Guerra Mundial, pues en la Segunda el soldado ha pasado ya a un segundo plano. Lo propio de este 
hombre sin nombre no es la acción, sino lo que está en "la zona de sombra de las acciones". El aura guerrera no le corresponde tanto al excombatiente como al caído que revela en la muerte nuestra relación elemental con la tierra: éste es la verdadera Figura de la Gran Guerra, cuyo sacrificio no puede ni debe haber sido en vano.

\begin{abstract}
¿A qué se debe el que la figura del Soldado Desconocido vaya claramente asociada al recuerdo de la primera guerra mundial, pero no al de la segunda? Se debe a que en la última resaltan con claridad las modalidades y los objetivos de la guerra civil mundial. Con ello vuelve a pasar a segundo plano lo propiamente bélico, el soldado. En cambio, el Soldado Desconocido de la primera guerra mundial continúa siendo un héroe, un domeñador de los mundos del fuego, que toma sobre sí grandes cargas en medio de aniquilaciones mecánicas. Ello lo convierte en un descendiente legítimo de la caballería de Occidente (Jünger, 1988, p. 52). ${ }^{13}$
\end{abstract}

\title{
La Segunda Guerra Mundial: el dolor de un emboscado en el vientre de Leviatán
}

Entonces se apodera de mí un asco de los uniformes, de las charreteras, de las condecoraciones, de las armas, cosas todas ellas cuyo brillo he amado tanto.

E. Jünger, Anotaciones del Cáucaso, 31 de diciembre de 1942.

${ }^{13}$ Sobre el Soldado Desconocido véase la estremecedora descripción que traza su hermano F. G. Jünger (1968, pp. 149-150): "No lleva sobre su cuerpo nada que le pertenezca, y en los bolsillos pocas cosas que puedan identificarlo. Carece hasta tal punto de nombre, es tan desconocido, que le cuelgan una ficha de hojalata por la cual se establece su nombre cuando cae, o cuando pierde la memoria. La muerte misma no tiene nada solemne; llega como un mecánico que se dedica a llenar las fosas comunes. Desplaza, destroza, pulveriza al hombre, envía nubes de gas sobre él y lo sepulta bajo tierra". 
Si en los fotolibros de los años treinta Jünger parece estar todavía imbuido del espíritu neoromántico del realismo heroico plasmado magistralmente en sus Tempestades de acero, en vísperas de la Segunda Guerra Mundial, su actitud ante la guerra experimenta un notable cambio. La máquina domina totalitariamente al hombre. Jünger comienza la redacción de sus monumentales Diarios de la Segunda Guerra Mundial el 3 de abril de 1939, apenas cinco meses antes de la invasión de Polonia por parte del ejército alemán, hace hoy más de ochenta años. El autor a quien supuestamente le habría incumbido "la mayor responsabilidad por haber preparado a la juventud alemana para el estado nazi, aunque él mismo nunca haya profesado el nazismo" (Kahler, 1997, p. 356), asiste con una provocativa indiferencia desde su apartada aldea de Kirchhorst a los dramáticos acontecimientos de aquellos meses. El viejo guerrero ha dado paso al nuevo teólogo, la acción militar al arte y la literatura. En la "Nota introductoria" al primer volumen de Radiaciones, el título que Jünger eligió para sus seis Diarios de la Segunda Mundial, Andrés Sánchez Pascual escribe a propósito del primer diario, Jardines y carreteras:

Pero lo decisivo de este primer diario es la visión de la guerra desde una perspectiva nueva, la del sufrimiento. Ahora el soldado no es ya para Jünger, como lo era en Tempestades de acero, el hombre de acción, el lansquenete lanzado a dar muerte al adversario. Ahora el soldado no es el hombre que mata y que triunfa -o que sucumbe gloriosamente-, sino que es el individuo sometido a la disciplina, amenazado por la muerte, expuesto al dolor. Y el uniforme militar no es ya una distinción propia de señores, sino que encarna una obligación ética, es un manto con el que cubrir y proteger a los débiles y amenazados" (Jünger, 1995a, pp. III-IV).

Las primeras entradas de Jardines $y$ carreteras son tan cándidamente domésticas que no permiten adivinar la tormenta de acero que se iba a desatar sobre los cielos de Europa el 1 de septiembre de 1939. Jünger se encontraba esos días trabajando en 
su novela Sobre los acantilados de mármol, cuyo título era al principio La reina de las serpientes y que la crítica ha leído como una alegoría anti nazi. El 16 de abril de 1939 suenan los primeros tambores de guerra en el diario. Ve pasar por la carretera cañones y más cañones, informándonos de que los alemanes han entrado en Bohemia, en Moravia y en Memel, mientras que los italianos lo han hecho en Abisinia. "Todos los signos indican que en breve habrá guerra; de ahí que obre bien contando que habré de suspender el trabajo. [...] En todo caso la pluma habrá de tomarse entonces un completo descanso, si exceptuamos el diario. Será preciso traspasar el trabajo a los ojos, pues no han de faltar espectáculos" (Jünger, 1995a, pp. 32-33).

Las observaciones botánicas y zoológicas se entremezclan en este primer diario con las reflexiones sobre la novela que está a punto de terminar y la descripción de sus lecturas y sueños. Entre estos últimos el que anota el 28 de abril de 1939: "Noche agitada. Primero se me aparecía Kniébolo, al que encontraba enclenque y melancólico y menesteroso de contacto. Me ofrecía bombones envueltos en magnífico papel dorado; me decía que le habían regalado cantidades enormes para el día de su santo". Nada nos hace sospechar que Kniébolo es el nombre secreto que Jünger va a dar en sus Diarios a Hitler. La entrada del 25 de abril es menos ambigua sobre el cariz de los acontecimientos de aquellos meses. Ese día le envían su cartilla militar, ocasión que aprovecha para comparar el presente con la atmósfera vivida en los días previos al comienzo de la Primera Guerra Mundial:

En estas semanas la política trae a la memoria la época que precedió inmediatamente a la Gran Guerra, la guerra del catorce. Lo que, sin embargo, resulta nuevo es la enorme emotividad de las masas, que contrasta cada vez más con el temible incremento de los medios de combate. [...] Hay un único factor que es terrible en todos los tiempos y que nunca deja de serlo -el ser humano; las armas son únicamente 
miembros que le han sido adosados y sentimientos a los que se ha otorgado forma (Jünger, 1995a, pp. 36-37). ${ }^{14}$

El 6 de mayo de 1939 Jünger se plantea revisar su ensayo Sobre el dolor para añadirle un capítulo sobre la amargura. ¿Por qué este repentino interés por el sentimiento de la amargura? ¿Acaso Jünger estaba amargado en los días previos al estallido de la Segunda Guerra Mundial? Según el diarista, que se encontraba ya en medio del camino de la vida, la amargura no se aposentaría en el hombre "hasta la segunda mitad de la vida, cuando, con las arrugas del rostro, se pone de relieve el carácter ineludible de las líneas del destino". Con esta frase, el mismo autor que había llamado en 1932 a la participación en el "nuevo orden" bajo la forma del "trabajo" parece hablar ahora en clave acerca de su resignación y amargura por el trágico destino de Alemania. Al conservar así la amargura de su propio sufrimiento, vituperado antes en los otros, Jünger perdía definitivamente la inocencia de su primera juventud pero acaso ganaba en conciencia y humanidad.

La orden de movilización le llega esta vez cuando se haya acostado leyendo (¿casualidad?) a Heráclito. ¡Con qué indiferencia acoge Jünger esta noticia! ¡Qué contraste con su entusiasmo en la guerra del catorce! Escribe el 26 de agosto de 1939: "A las nueve de la mañana, cuando me hallaba muy cómodo en el lecho estudiando a Heráclito, me ha subido Louise la orden de

${ }^{14}$ De este comentario no se debe deducir que la población marchara con entusiasmo a la guerra. La verdad histórica más bien dice lo contrario. Asimismo, la última frase parece incurrir de nuevo en la minusvaloración de las armas, no obstante el papel cada vez más decisivo del tema de la técnica en la ensayística de Jünger. Contrástese con lo que lúcidamente escribía Ortega y Gasset (1972, p. 184): "Una modificación de las armas de combate acarrearía una distinta configuración de la sociedad". Para la cuestión de la técnica de $E l$ trabajador a Abejas de cristal, véase la reciente publicación de Alsina Calvés (2021, pp. 157 y ss.). 
movilización; dice que el 30 de agosto he de presentarme en Celle. La he recibido sin mucha sorpresa, pues la imagen de la guerra iba perfilándose con rasgos cada vez más netos a cada mes que pasaba, a cada semana que transcurría" (1995a, p. 62).

Dos días después, el 28 de agosto, realiza esta extraña anotación: "Continúa la movilización en todos los países. Aún habría tiempo para el deus ex machina. Ahora bien, ¿qué es lo que éste podría aportarnos? Es tal la acumulación de cosas en litigio que el único que puede rematar el trabajo es el Fuego". ¿Es esta retórica apelación a lo elemental la forma que tiene Jünger de decirnos que no fue posible la paz? ¿De nada habría servido entonces la "tarea unificadora" por la que supuestamente se sacrificara el Soldado Desconocido? De lo que no cabía duda es que esta vez la guerra iba a cumplir el sueño de Jünger de convertirse en una auténtica "movilización total". Pero el precio a pagar sería demasiado alto para él: la lucha no podría vivirse ya como "experiencia interior", sino simple y llanamente como trabajo. Pronto veremos, en efecto, cómo la experiencia templada en sangre y fuego del soldado de la Gran Guerra tiene que ceder a la de la persona singular expuesta exclusivamente al dolor.

El día en que le comunican su ascenso a capitán de la Wehrmacht, el 30 de agosto, escribe: "Partida. Arriba, no sin ironía, he estado mirándome en el espejo, con mi uniforme de alférez. De todos modos, algo similar estará ocurriendo hoy en Europa a muchos hombres que en ningún momento se imaginaron que volverían a prestar servicio militar" (Jünger, 1995a, p. 63). Y el día de la invasión de Polonia, el 1 de septiembre de 1939, anota como si no fuera la cosa con él: "En el desayuno me ha preguntado el camarero, poniendo una cara muy expresiva, si había oído los noticiarios. Según ellos hemos entrado en Polonia". Irónico se muestra también cuando a los pocos días le hacen participar en un cursillo: "Tras haber pasado un breve permiso en casa me 
encuentro ahora en Blankenburg, donde estoy participando en un cursillo. Todas las guerras comienzan con cursillos" (Jünger, 1995a, p. 65).

El primer domingo que pasa en Blankenburg, el diarista lee las pruebas de Sobre los acantilados de mármol. Se refiere al esfuerzo que le cuesta dar con el giro adecuado y lo achaca, sorprendentemente, a la hostilidad de Ares hacia las Musas. Las armas y las letras han dejado de estar en armonía, el escritor y el soldado ya no se encuentran en la misma persona. ${ }^{15}$ El Capitán, como lo llamaba su amigo Carl Schmitt, parece hallarse "sometido a una presión enorme" y el simple saludo de una mujer lo interpreta como si un camarada le señalase el camino hacia la luz. $\mathrm{Y}$ añade: "Así es como uno oye, en el concierto a menudo demoníaco de las tempestades, la voz de la Patria, y no puede errar si la sigue" (Jünger, 1995a, p. 68). Una frase que quizá oculte la trágica decisión que algunos alemanes acabarían tomando en los años siguientes: la de buscar un peligroso equilibrio entre su oposición al régimen nazi y a Hitler y la lealtad hacia su país y a su ejército.

Las órdenes de traslado se suceden en aquellos días de octubre de 1939. El 10 se halla en Bothfeld y anota en su diario una reflexión sobre la guerra donde se la compara con el monstruo marino descrito en el Libro de Job, una imagen recurrente en la obra del autor de La paz y de la que también se va a servir Carl Schmitt en su actualización del estado hobbesiano. En efecto,

${ }^{15}$ Jünger, 1995a, p. 156: "En ciertas encrucijadas de nuestra juventud podrían aparecérsenos Belona y Atena -la primera con la promesa de enseñarnos el arte de guiar veinte regimientos al combate de manera que estuvieran en su puesto en el momento de la batalla, mientras que la segunda nos prometía el don de juntar veinte palabras de manera que formasen una frase perfecta. Y pudiera ser que escogiésemos el segundo de los laureles; éste crece, más raro e invisible, en las pendientes rocosas". 
La guerra se parece a Leviatán, del cual lo único que asoma por encima de las aguas son unas pocas escamas o una aleta -la materia es demasiado compacta como para que la mirada pueda articularla y ello hace que la sensación que se produce sea la de irrealidad. Los seres humanos sienten cómo cerca de ellos se mueven grandes masas, pero no captan ni la dirección que llevan ni la meta a que se dirigen; también barruntan quizá que dentro de la cáscara de estos días hay escondidas otras cosas espectáculos de índole nueva y desconocida. Y así ocurre también que los humanos quedan al descubierto, sin protección, porque no conocen el camino que sigue el Destino (Jünger, 1995a, p. 71). ${ }^{16}$

No hace falta seguir citando Jardines y carreteras para cerciorarse de que el futuro capitán del Estado Mayor de las fuerzas de ocupación en Francia ha comprendido claramente desde su "exilio interior" que el tiempo del realismo heroico ha pasado. Las noticias que le llegarán más tarde del frente del Este le convencerán acerca de la muerte de la vieja caballería y, en última instancia, de la inevitabilidad de la catástrofe alemana. "El sufrimiento crece hasta tal punto que por fuerza queda excluido lo heroico", escribe en $L a$ emboscadura en referencia a la Segunda Guerra Mundial. En este ensayo aparece por primera vez el Emboscado, junto al Trabajador y el Soldado Desconocido, como una de las "figuras" de nuestro tiempo. Sin duda, Jünger, que había esbozado este tipo existencial en Sobre los acantilados de mármol, se ha estilizado a sí mismo como un Emboscado en el vientre de Leviatán, es decir, como alguien que no dudó en ofrecer -0 al menos así lo creyó él- una "resistencia espiritual" a la tiranía nazi. Ahora bien, dado que la resistencia no es suficiente (Jünger dixit), ¿habría debido también el

${ }^{16}$ En abril de 1945 aparece de nuevo la imagen de Leviatán, pero para caracterizar esta vez el espectáculo de los tanques norteamericanos en lo que parece una "simbólica" persecución de Hitler. Véase Jünger (1992, p. 368): “despiertan en mí la impresión de una mágica excursión de pesca con caña, tal vez para capturar a Leviatán”. Para un comentario crítico de este pasaje véase Blumenberg (2010, pp. 62-67). 
Emboscado contraatacar? La respuesta a esta pregunta depende del presunto efecto causado por su manifiesto $L a$ paz, cuya primera redacción data del año 1941, como llamamiento a la juventud europea y del valor que otorguemos a su más que discreta participación en la conspiración que llevó al atentado del 20 de julio de 1944 contra Hitler. ${ }^{17}$ Pero sobre este último punto, el capitán Jünger parece haberse mostrado más bien cauteloso: "Pero ante todo yo estaba convencido de que, sin un Sila, todo ataque a la democracia plebiscitaria conduciría a un reforzamiento ulterior de lo inferior; y eso fue también lo que ocurrió y lo que sigue ocurriendo" (Jünger, 1995a, p. 15). En cualquier caso, ahí quedan sus diarios de guerra como un ejemplo, en palabras de Hannah Arendt, "de las inmensas dificultades a que se expone un individuo cuando quiere conservar intactos sus valores y su concepto de la verdad en un mundo en que verdad y moral han perdido toda expresión reconocible" (1993, p. 47).

En un mundo así, ¿pudieron acudir los alemanes por segunda vez a la obra de Jünger para leer la catástrofe?, ¿brindaron sus libros algún consuelo en aquellos terribles años de tribulación? Al parecer un número considerable de alemanes estaba leyendo a nuestro "esteta en guerra" cuando estalló la Segunda Guerra Mundial. "Leer a Jünger era reformular la confrontación como una tragedia épica que dejaba al descubierto un acercamiento existencialista a los acontecimientos. Los soldados encontraban en él a un autor que reconocía el carácter implacable de la guerra que estaban librando y les infundía valor para aceptar la brutalidad de la confrontación" (Fritzsche, 2009, p. 283). Este era el caso del futuro

${ }^{17}$ Véase Beevor (2009, p. 411) para el supuesto ofrecimiento de sus ideas al mariscal Rommel "acerca de la paz que había que firmar con los aliados". Según Jünger, Rommel habría leído su texto sobre $L a$ paz, el cual le parecía "un buen punto de partida, sobre el que se podía trabajar". Véase Jünger (1996); Gnoli y Volpi (1998, p. 64) y lo que dice sobre esta cuestión en el importantísimo prólogo de Jünger (1995a, pp. 15-16).

Argumentos de Razón Técnica, n² 24, 2021, pp. 142-176 
novelista Heinrich Böll para quien Jünger lograba describir con claridad las circunstancias en las que él mismo se encontraba como soldado. De esta forma, "los términos existencialistas en los que se describía la guerra evitaban las cuestiones de la responsabilidad y revestían de una dimensión estética la impotencia y la pasividad" (Fritzsche, 2009, p. 284) ¿Qué lectura hacían los libros de Jünger de la catástrofe alemana? "Hasta cierto punto, era la estética de la guerra total sin el abrazo del nazismo, el fascismo alemán sin Hitler". Según Peter Fritzsche:

Uno tras otro, los lectores de Jünger naturalizaron la calamidad de manera que dejaron de reconocer a los protagonistas o perpetradores y ya no veían a los judíos, los nazis o los rusos. Lo que estos alemanes habían terminado viendo era la condición general de dispersión o naufragio que creían compartir con todos sus contemporáneos en un universo nuevo [...] Leer a Jünger en Alemania en 1945 era al mismo tiempo espeluznante y consolador (2009, p. 285-287).

La guerra de agresión y la guerra de exterminio, la guerra total teorizada por el general Ludendorff durante el primer gran conflicto bélico (¿hasta qué punto la idea jüngeriana de totale Mobilmachung se aproxima inquietantemente a este concepto?), y aclamada fanáticamente por Goebbels tras Stalingrado, echaban por tierra definitivamente los ideales de heroísmo de la guerra caballeresca que el autor de El corazón aventurero defendía al mismo tiempo con toda la ingenuidad de su germano corazón. Ahora bien, si alguna lección había que extraer de la Primera Guerra Mundial, primer episodio de una "guerra civil europea" a juicio de algunos, ${ }^{18}$

${ }^{18}$ Véase Traverso (2009). El concepto "guerra civil europea", de raigambre schmittiana, apareció ya antes con distinta periodización en el historiador revisionista alemán Nolte (1994). Pero como afirma Fritzsche (2009, p. 286): "Narrar los años 1914-1945 como treinta años terriblemente autodestructivos de guerra o guerra civil también fue una forma de confiscar las causas políticas de la segunda guerra mundial y las implacables ambiciones utópicas de los nazis. Ello 
es que "la particularidad estratégica más distintiva será la cruda y radical guerra de agresión" (Benjamin, 1991, p. 48) y, por consiguiente, que "la guerra en su forma actual ya no ofrece oportunidad para cumplir el antiguo ideal heroico" (Freud, 1973, p. 3214). Y así, lo heroico quedaba excluido incluso en relación a la guerra del catorce, pues en los ensayos de comienzos de los años treinta como El trabajador o Sobre el dolor, Jünger se había percatado de la triple alianza que se daba en aquella "batalla de material" entre técnica, voluntad de poder y nihilismo, la cual viene a complementar la que se daba asimismo entre trabajo, técnica y guerra. "La fuerza de combate de la persona singular" había dejado de tener en este escenario "un valor individual", para pasar a tener un valor meramente funcional, donde todo intento por pintar con colores románticos o idealistas la situación abocaba directamente al absurdo (Jünger, 1993, p. 108). Si bien Jünger no creyó incompatible en este contexto asumir la actitud de un "nihilismo heroico", bajo el Tercer Reich le sería de todo punto imposible mantener el pathos épico que había alentado sus Tempestades de acero. Como él mismo llegó a admitir en su "último libro", la Segunda Guerra Mundial se había adelantado al siglo XXI, y ello hasta el punto de que algún historiador ha podido definirla paradójicamente como "tercera" guerra mundial. ${ }^{19}$

creó equivalencias entre los estados beligerantes y, en consecuencia, hizo que se tendiera a pasar por alto el papel central que el racismo y el antisemitismo tuvieron en el Tercer Reich".

19 "La primera guerra mundial todavía se libró con las reglas del siglo XIX; la segunda se adelantó hasta el siglo XXI" (Jünger, 1997, p. 191); "y por mucha que estuviese unida la campaña [Barbarroja] estratégicamente con la totalidad de la guerra, significaba sin embargo, en su forma de ser y en su moral, algo completamente nuevo: algo parecido a una tercera guerra mundial" (Fest, 1974, p. 301). 


\section{CODA}

La experiencia de la guerra constituye la clave para entender la obra de Ernst Jünger. Como tal, ésta constituye el barómetro de un siglo que solo conoció fuego, sangre, dolor y muerte. Las figuras o tipos fundamentales de su pensamiento: el Trabajador, el Soldado Desconocido, el Emboscado han probado su dominio, por lo pronto, en las dos guerras mundiales. En efecto, la moderna Era del Trabajo se había insinuado en la Gran Guerra (Jünger, 1995b, pp. 93-101), cuya imagen intemporal no es otra que la sagrada víctima inmolada del Soldado Desconocido. Pero sólo en la Segunda Guerra Mundial, cuando el uniforme ha dejado de ser un escudo protector contra el dolor por ser éste la única experiencia verdaderamente elemental, ha podido Jünger concebir el tipo del Emboscado, una figura que anticipa ya a la del Anarca y con la que enfrentará también la inmediata postguerra, la Guerra Fría y la Era Atómica. El dolor que hizo imposible el heroísmo en la segunda contienda bélica contiene, en compensación, un potencial salvífico que constituye la mayor esperanza de nuestro atribulado mundo actual. Así como el Soldado Desconocido de la primera de las guerras mundiales debía haber realizado una "tarea unificadora" entre los pueblos, es de esperar que la fuerza curativa de los inhumanos padecimientos soportados en la segunda señale por fin a la humanidad el camino de la paz perpetua soñada por Kant. Pero no parece haber sido este el caso si vemos esta guerra solo como una fase de un conflicto único, cuyo término no se produjo de facto hasta el fin de la Guerra Fría, simbolizado en la caída del Muro de Berlín. Dice Jünger en un pathos que recoge la tremenda enseñanza del castigo siberiano de Raskolnikov: "En la experiencia y el conocimiento de aquellos años en el Este, incluido el destino del prisionero, se esconde un capital de dolor todavía inexplorado, la 
auténtica salvación de nuestra época" (Jünger y Heidegger, 1994, p. $33) .{ }^{20}$

El soldado-trabajador de la Primera Guerra Mundial que muere sin nombre y a quien el cielo sirve de urna funeraria, no podrá seguir siendo un héroe en medio del automatismo de la guerra civil mundial, que es como nuestro poeta-filósofo conceptúa la segunda de las guerras mundiales. Como implicado en la corriente demoníaca de su tiempo, al propio autor no le quedó aquí sino un solo camino: el camino de la emboscadura, el camino de quien resurge de la catástrofe templado por el dolor. Pero el Emboscado, como el mismo Jünger reconoce, no es un soldado, ni presumiblemente el trabajador otrora exaltado, sino la "persona singular" (acaso un guerrillero) cuyas armas no pueden ser físicas o políticas, pues la resistencia que opone al automatismo que amenaza con aniquilar la dignidad humana descansa únicamente en la libertad interior que se oculta en su propio pecho. Pero aunque no sea el Soldado de la guerra del catorce, un Emboscado sigue siendo un luchador, y así lo manifiesta el lenguaje marcial de $L a$ emboscadura, una obra que podría ser interesante leer junto a la Teoría del partisano (1963), de Carl Schmitt. ${ }^{21}$ El Soldado

${ }^{20}$ En correspondencia con esta idea, Jünger piensa que "[e]l cambio esencial de nuestro siglo se ha producido precisamente a partir de su mitad, desde 1945 en adelante", pues solo la Segunda Guerra Mundial nos habría hecho "descender a las profundidades del Mälström, al vórtice del nihilismo (Gnoli y Volpi, 1998, pp. 18-20). Lo que Jünger parece no comprender es que este mismo nihilismo convirtió en absurda la pretensión de seguir buscando a la muerte de millones algún sentido. Como escribe el gran historiador alemán Reinhart Koselleck (como se cita en Oncina Coves, 2007, p. 58): "Desde la Segunda Guerra Mundial... quien pregunta por el sentido de la muerte de soldados más bien provoca... Todo el paisaje iconográfico tematiza ahora la imposibilidad de fundar un sentido [...] la absurdidad misma".

${ }^{21}$ Según De Benoist (2008, p. 52): "El Rebelde sigue siendo un combatiente, como el Soldado del frente, pero es un combatiente activo que repudia la impersonalidad, pues tiene la intención de preservar su libertad con respecto a la 
Desconocido pertenecía todavía al séquito de la Figura del Trabajador, era su primera víctima sacrificial. ¿Habrá conseguido entretanto el Emboscado sustraerse al doloroso dominio técnico de la Figura? ¿O tendrá que contar todavía con ésta para dejar atrás el nihilismo que el viejo guerrero abrazara heroicamente en su juventud? No resulta extraño que este Dichterphilosoph retrocediese ante la sombra alargada de ese titán del siglo XX que pone su pie en el XXI: "A la primera visión de los titanes sigue el espanto: véase el apartamiento de Chirico respecto de sus obras tempranas: algo semejante me sucedió con la figura del trabajador" (Jünger, 1987, 165). ${ }^{22}$ Sin embargo, podríamos preguntarnos si la emboscadura no es tanto una nueva respuesta de la libertad como el movimiento de retirada de un espíritu aristocrático que no distinguía entre dictadura y democracia, y que simplemente se negaba a asumir en el espacio público, como Mann dijo de Spengler, que "hizo cosas terribles para allanar el camino de lo que vendría, y fue uno de los primeros en tocar las notas que hoy nos ensordecen" (como se cita en Herman, 1998, p. 258). Pues tras la Shoà la imagen del bosque oscuro y lleno de silencios no podía ser el lugar numinoso de la Palabra, sino el de su más absoluto acallamiento: la selva interior donde se embosca el Waldgänger escondía para los alemanes un claro ominoso de impunidad donde los mauritanos de la cruz gamada recién habían instalado las barracas de los desolladores. Los poetas no olvidan:

causa que defiende". Este ensayo aclara la diferencia entre figura y tipo en el pensamiento de Jünger. Para De Benoist, solo el Trabajador cumple con la definición de figura dada por el solitario de Wilflingen.

${ }^{22}$ Véase (Jünger, 1987, p. 18) sobre la glorificación de la guerra: "Hoy, en la era de la bomba atómica, Homero tendría que disculparse por haber glorificado la guerra. También Schiller y Hölderlin necesitarían purificarse a este respecto". Pero ¿no debería haberse incluido Jünger en la nómina de los autores que necesitaban semejante purificación? Para los pronósticos de Jünger sobre nuestro tiempo, véase Wegener (2006). 
alli Buchenwald, el apacible bosque de hayas, sus hornos malditos... (Quasimodo, 1985, p. 80).

Con motivo de su quincuagésimo cumpleaños, el 29 de marzo de 1945, cuando ya había sido apartado del Ejército y no faltaba mucho para que la bandera roja ondease en el Reichstag en ruinas para consumar el hundimiento, este frío "esteta en guerra" de mirada entomológica creía en el diario que tituló Hojas de Kirchhorst haber alcanzado "una edad avanzada", sobre todo teniendo en cuenta el peligro al que se había expuesto en las dos guerras mundiales: "en la primera, en los remolinos de la batalla de material, y durante la segunda, en los oscuros y peligrosos vericuetos del mundo de los demonios" (Jünger, 1992, p. 358). Jünger había sobrevivido para contarlo. Después de la Segunda Guerra Mundial, en la memorable confrontación epistolar que mantuvieron sobre el nihilismo europeo, Martin Heidegger no habría pasado por alto que su viejo amigo Jünger "no participa ya en aquella acción del nihilismo activo, que también en $E l$ trabajador es pensada en sentido nietzscheano en la dirección de una superación". Y añadía: "Sin embargo, el no-tomarparte no significa en absoluto estar fuera del nihilismo" (Jünger y Heidegger, 1994, p. 81). Nos parece que en este punto la reprensión del filósofo no es justa, pues si bien es cierto que el hecho de no participar no colocaba al autor de Sobre la línea fuera del nihilismo, no por ello debe subestimarse la libertad interior de la persona singular que decide oponer una "resistencia espiritual" a su enorme poder 
de coacción, y es que parafraseando aquí las sabias palabras del hermano Othón en Sobre los acantilados de mármol, al referirnos a la época en que Jünger no creyó errar al seguir la voz de la Patria, no debemos olvidar, en contraste con el compromiso contraído con el nazismo por sus amigos Carl Schmitt y el mismo Heidegger, "que el error únicamente se convierte en falta cuando se persiste en él" (Jünger, 1962, p. $38)$.

\section{Bibliografía}

ABELLÁN, J. (1997). Nación y nacionalismo en Alemania. La cuestión alemana (1915-1990). Tecnos.

ALSINA CALVÉS, J. (2021). Para comprender a Heidegger. Ediciones Fides.

ARENDT, H. (1993). Besuch in Deutschland. Rotbuch. BEEVOR, A. (2009). El Día D. La batalla de Normandía, trad. de Teófilo de Lozoya y Juan Rebasseda. Crítica.

BÉLAND, M. (2009). La baïonnette, la plume et le marteau. Ernst Jünger, figure de l'intellectuel formé au combat. En M. BÉLAND y M. DUTRISAC (dir.), Weimar ou l'hyperinflation du sens: portraits et exils (pp. 31-51). Les Presses de 1'Université Laval.

BENJAMIN, W. (1991). Iluminaciones IV. Para una crítica de la violencia y otros ensayos, trad. de Roberto Blatt. Taurus. BENOIST, DE A. (2008). Soldier, Worker, Rebel, Anarch: An Introduction to Ernst Jünger. The Occidental Quarterly, 8 (3), 49-59. 
BLUMENBERG, H. (2010). El hombre de la luna. Sobre Ernst Jünger, trad. de Pedro Madrigal. Pre-Textos.

BREUER, S. (1996). Anatomie de la Revolution conservatrice. Éditions de la Maison des sciences de l'homme.

DUPEAUX, L. (dir.). (1992). La Revolution Conservatrice dans l'Allemagne de Weimar. Éditions Kimé.

FEST, J. C. (1974). Hitler: un estudio sobre el miedo, vol. 2, trad. de Guillermo Raebel. Noguer.

FREUD, S. (1973). ¿Por qué la guerra? En Obras completas, vol. III, trad. de L. López-Ballesteros (pp. 3207-3215). Biblioteca Nueva.

FREUD, S. (1996). Consideraciones de actualidad sobre la guerra y la muerte. En El malestar en la cultura, trad. de Luis López Ballesteros y de Torres (pp. 96-123). Alianza.

FRITZSCHE, P. (2009). Vida y muerte en el Tercer Reich, trad. de Luis Noriega. Crítica.

GNOLI, A. y VOLPI, F. (eds.). (1998). Los titanes venideros. Ideario último, trad. de Atilio Pentimalli. Península.

HERMAN, A. (1998). La idea de decadencia en la historia occidental, trad. de Carlos Gardini. Editorial Andrés Bello.

JÜNGER, E. (1962). Sobre los acantilados de mármol, trad. de Tristán la Rosa. Destino.

JÜNGER, E. (1987), El autor y la escritura, trad. de Ramón Alcalde, Gedisa.

JÜNGER, E. (1988). La emboscadura, trad. de Andrés Sánchez Pascual. Tusquets.

JÜNGER, E. (1990). El trabajador. Dominio y Figura, trad. de Andrés Sánchez Pascual. Tusquets. 
JÜNGER, E. (1992). Radiaciones. Diarios de la Segunda Guerra Mundial. Memorias, vol. 2, trad. de Andrés Sánchez Pascual. Tusquets.

JÜNGER, E. y HEIDEGGER, M. (1994). Acerca del nihilismo, trad. de José Luis Molinuevo. Paidós.

JÜNGER, E. (1995a). Radiaciones. Diarios de la Segunda Guerra Mundial. Memorias, vol. 1, trad. de Andrés Sánchez Pascual. Tusquets.

JÜNGER, E. (1995b). Sobre el dolor seguido de La movilización total y Fuego y movimiento, trad. de Andrés Sánchez Pascual. Tusquets.

JÜNGER, E. (1996). La paz seguido de El nudo gordiano, El Estado Mundial y Alocución en Verdún, trad. de Andrés Sánchez Pascual. Tusquets.

JÜNGER, E. (1997). La tijera, trad. de Andrés Sánchez Pascual. Tusquets.

JÜNGER, E. (1998). Tempestades de acero, trad. de Andrés Sánchez Pascual. Tusquets.

JÜNGER, E. (2001). Politische Publizistik 1919-1933. KlettCotta.

JÜNGER, E. (2005). El mundo transformado seguido de El instante peligroso. Pre-Textos.

JÜNGER, E. (2013). Diario de guerra (1914-1918), trad. de Carmen Gauger. Tusquets.

JÜNGER, E. (2014). El teniente Sturm, trad. de Carmen Gauger. Tusquets.

JÜNGER, F. G. (1968). Perfección y fracaso de la técnica, trad. de H. A. Murena y D. J. Vogelmann. Ed. Sur.

KAHLER, E. (1977). Los alemanes, trad. de Juan José Utrilla. FCE. 
KING, J. (2003). "Wann hat dieser Scheißkrieg ein Ende?" Writing and Rewriting the First World War. Antaios.

KUNICKI, W. (1999). Erich Maria Remarque und Ernst Jünger, ein unüberbruckbärer Gegensatz? En THOMAS F. SCHNEIDER (ed.), Kriegserlebnis und Legendenbildung: das Bild des "modernen" Krieges in Literatur, Theater, Photagraphie und Film (pp. 291-308). Rasch.

MOHLER, A. (1950). Die Konservative Revolution in Deutschland 1918-1932. Friedrich Vorwerk.

NOLTE, E. (1994), La guerra civil europea, 1917-1945, trad. de Sergio Monsalvo Castañeda, Julio Colón Gómez y Adriana Santoveña Rodríguez. FCE.

OCAÑA, E. (1993). Más allá del nihilismo. Meditaciones sobre Ernst Jünger. Universidad de Murcia.

ONCINA COVES, F. (2007). Necrológica del Outsider Reinhart Koselleck: el "historiador pensante" " y la polémica de los historiadores. Isegoría, 37, 35-61.

ORTEGA Y GASSET, J. (1972). La interpretación bélica de la historia (1925). El espectador, t. VI (pp. 179-195). Revista de Occidente.

QUASIMODO, S. (1985). Y enseguida anochece $y$ otros poemas, trad. de Carlo Frabetti. Ediciones Orbis.

REMARQUE, E. M. (1984), Sin novedad en el frente, trad. de Manuel Serrat. Planeta/Bruguera.

RODRÍGUEZ SUÁREZ, L. P. (2013). E. Jünger: escritura de guerra y pensamiento antropológico. Thémata. Revista de Filosofía, 48, 191-199.

ROSSI, L. A. (2003). La política del heroísmo: Ernst Jünger entre 1920 y 1932. Prismas. Revista de Historia Intelectual, 7, 51-72. 
SÁNCHEZ DURÁ, N. (2001). Lontano dagli occhi, lontano dal cuore: conciencia técnica y crítica del pacifismo en el joven Jünger. Logos. Anales del Seminario de Metafisica, 3, 143-177.

SÁNCHEZ DURÁ, N. (ed.). (2002). Ernst Jünger: Guerra, técnica y fotografía. Vicerectorat de Cultura, Universitat de València.

TRAVERSO, E. (2009). A sangre y fuego. De la guerra civil europea (1914-1945), trad. de Miguel Ángel Petrecca. PUV. VOLMERT, J. (1985). Ernst Jünger: "In Stahlgewittern". Wilhelm Fink Verlag.

WEGENER, H. (ed.). (2006). Ernst Jünger y sus pronósticos del Tercer Milenio. Editorial Complutense.

WERNEBURG, B. (1992). Ernst Jünger and the Transformed World. October, 62, 42-64.

ZWEIG, S. (2001). El mundo de ayer. Memorias de un europeo. El Acantilado. 
